University of New Orleans

ScholarWorks@UNO

2015

\title{
Public Participation GIS and Neighbourhood Recovery: Using Community Mapping for Economic Development
}

Michelle M. Thompson PhD, GISP

University of New Orleans

Follow this and additional works at: https://scholarworks.uno.edu/plus_facpubs

Part of the Urban Studies and Planning Commons

\section{Recommended Citation}

Thompson, Michelle M. "Public Participation GIS and Neighbourhood Recovery: Using Community Mapping for Economic Development." International Journal of Data Mining, Modelling and Management 7 (1) : 24-38

This Article is brought to you for free and open access by the Department of Planning and Urban Studies at ScholarWorks@UNO. It has been accepted for inclusion in Planning and Urban Studies Faculty Publications by an authorized administrator of ScholarWorks@UNO. For more information, please contact scholarworks@uno.edu. 


\title{
Public participation GIS and neighbourhood recovery: using community mapping for economic development
}

\author{
Michelle M. Thompson \\ Department of Planning and Urban Studies, \\ University of New Orleans, \\ 301 Milneburg Hall, New Orleans, LA 0148, USA \\ Email: mmthomp1@uno.edu
}

\begin{abstract}
In 2005, New Orleans, Louisiana experienced an interruption in its neighborhood life cycle due to Hurricane Katrina. While federal, state and local administrative policies have tried to manage the process of recovery, the non-profit sector has been a key to the recovery. This paper will examine the case study of the Beacon of Hope Resource Centre (BOH) whose ability to collect data, expand citizen engagement and influence policy made a positive impact upon economic development through public participation geographic information systems (PPGIS) with the Regional Planning Commission and the Department of Planning and Urban Studies, University of New Orleans. This successful neighbourhood planning model provides an understanding of how PPGIS partnerships can support and encourage community engagement and economic development pre- and post-disaster.
\end{abstract}

Keywords: geographic information systems; GIS; hurricane Katrina; public participatory GIS; community planning; New Orleans.

Reference to this paper should be made as follows: Thompson, M.M. (2015) 'Public participation GIS and neighbourhood recovery: using community mapping for economic development', Int. J. Data Mining, Modelling and Management, Vol. 7, No. 1, pp.24-38.

Biographical notes: Michelle $M$. Thompson is an Assistant Professor at the Department of Planning and Urban Studies and Geography, University of New Orleans teaching geographic information systems, community development and urban public finance, housing, urban studies and land use planning. She received her Master's in Regional Planning in 1984 and $\mathrm{PhD}$ in 2001 from the Department of City and Regional Planning, Cornell University and her Bachelor of Arts in Policy Studies from Maxwell School of Citizenship and Public Affairs from Syracuse University in 1982. Her research focuses the application of public participation geographic information systems (PPGIS) using the web-based mapping service, WhoData.org. She is the Assistant Director of Cross World Africa, Inc., a 504(c) 3, providing cultural, education and micro-finance resources in Sub-Saharan Africa. 


\section{Introduction}

'Katrina +5 ' has become the new means by which those associated with the City of New Orleans have recreated their time of reference the years following hurricane Katrina. Since 2005 , the city administration struggled to manage the multi-faceted public policy and planning issues that were exacerbated after the storm. In 2010, the City Council approved the Master Plan, incorporating recovery goals while identifying ways to combat existing and future challenges. The recovery planning processes met with significant criticism and cynicism since there were several variations culminating with the 'Unified New Orleans Plan' (UNOP). It remained clear that the federal, state and city governments, nor private or non-profit sectors had the experiential short term model plan that would address systemic issues, meet urgent needs or predict future implications of these decisions. The Master Plan reflects the desire to creatively expand public participation with its requirement to have 'Community engagement' throughout the planning process (City of New Orleans, 2010b). While this is not a novel idea, the New Orleans Master Plan has the force of law and recognises the impact neighbourhood organisations made in responding to community needs 'Post Katrina'. The contributions made by both citizens and neighbourhood organisations in renewal and recovery efforts “...has generally been welcomed by scholars and planning officials, who recognize the importance of citizen participation in planning and understand the value of the local knowledge that neighbourhood residents possess (Gans, 1991; Ghose, 2001; Handler, 1996; Healy, 1997) New Orleans" existing and new neighbourhood groups and community based organisations played a significant role in aiding in the process of recovery early on. In response to the crisis, many new community organisations that focused on social service, development, education, infrastructure, environment, etc. were created. In addition, there were individuals, organisations and institutions (from local to international) that responded to the crisis in a wide variety of ways. As of 6 March 2011, a total of '272 neighbourhood groups and organisations' were registered with the Neighbourhood Planning Network (NPN, 2011). Given a significant influx of people and resources, there were still concerns that many lacked representation (or in some cases an overrepresentation) of residents by organisations or were not included for a variety of issues (e.g., language, location, disability, and education). When residents began to return in the fall of 2005 and the winter of 2006, they needed information about how to get services, whether their neighbourhoods were safe to occupy, if they would have police and fire protection, and what the city's plans were (Nelson et al., 2007).

One of the criticisms by many local residents had been how resources were managed by both government and the non-profit sectors. They complained that the lack of data sharing prevented a greater return on the investment of the volunteer labour, materials and time dedicated to rebuilding efforts. The Louisiana Land Trust Road Home program met with criticism due to the lack of information management but also that inability to share critical data with federal, state and local agencies who, at times, were working with the same resident. The information services required to integrate the needs of the person with the place (e.g., their residence) remains a concern.

In an effort to increase the visibility of the resident concerns, as well as, provide information on the status of properties, community leaders began conducted neighbourhood needs assessments using property condition surveys. There was a disparity, and lack of continuity, in the data collection process since some 
neighbourhoods were able to participate with the assistance of neighbourhood organisations, volunteers or with colleges/universities. Many looked to city government, particularly the City Planning Commission or the City of New Orleans Geographic Information Systems Department, but they were met with limited response. The former lost the ability to function due to losses in staff while the latter given the enormity of the task, and the loss of knowledge from all sectors, the gap of historical knowledge and information from which to base future planning decisions was scarce. Generations of local knowledge evaporated and/or became disjointed after the city's evacuation. The people and places once familiar were immediately reframed when the water receded and former residents in-migrated. No longer was the corner store part of the familiar - it had become a distant memory. It became increasingly important to capture local knowledge based upon oral histories but also based upon surveys of existing conditions (ACORN/University Collaborative, 2007). These surveys were turned into physical and virtual maps using a variety of media. The maps, and the data that they were based upon, were typically not shared within or between organisations. There are cases where universities assisted communities with multiple surveys but never provided a static or electronic map in any form. This violated the trust of the community and made it more difficult for other university scholars to aid the community in a similar way.

By creating a series of maps, this local knowledge was captured and a wider spectrum of participation was achieved. This spectrum could range from providing a single data collection event to participating in periodic collection of data for mapping services. Visualisation is essential for drawing out maximum public participation because it is the only common language that all participants can relate to (Kheir, 1999). Given the pre-Hurricane Katrina disparities in access to ideas, services and information in New Orleans, a different way to inserting residents into the collaborative planning process (in the short and long-term) was needed.

\section{Using local knowledge and e-model of citizen participation}

The idea of collecting data seems relatively simple enough. The challenge for the community activists turned data information specialists was/is that the type of requisite education, training and level of sophistication to understand the nuances of 'informed' data collection may not be readily available within the organisation. The benefits of public participation and the use of geographic information systems (GIS) technology, to enhance community engagement have been widely documented. The integration of public data with local knowledge is not easily obtained but is a goal worth achieving. Local knowledge should never be ignored by planners seeking to improve the lives of communities experiencing the greatest risks (Corburn, 2003).

GIS technology has allowed public, private and academic environments to create new ways of thinking, communicating, coordinating and interacting. One of the most important aspects is that public participation geographic information systems (PPGIS) moves the conversation from the 'top down' to a 'bottom up' model of citizen participation (Talen, 1999, 2000). Abbott suggests that in order to achieve such a goal, participatory GIS methodologies need to be established and field tested. It is important that participatory GIS build upon the successes of existing participatory development concepts and methods (Abbott et al., 1998). Many have considered the basic problem of GIS and its ability to meet the needs of the community through these loosely-defined 
relationships with projects that may, or may not, be generalisable. GIS has emerged as an elitist, anti-democratic technology by virtue of its technological complexity and cost (Ghose, 2001). However, PPGIS is based upon the citizen participation theoretical model of community engagement. With the e-participation ladder, or technology-supported participation, citizens have multi-directional input with significant feedback in order to make informed decisions (Carver et al., 2001). The notion that citizens cannot effectively and fully participate in all aspects of neighbourhood revitalisation is challenged. The definition of 'citizen' and the level of engagement vary with the community.

Figure 1 The e-participation ladder (see online version for colours)

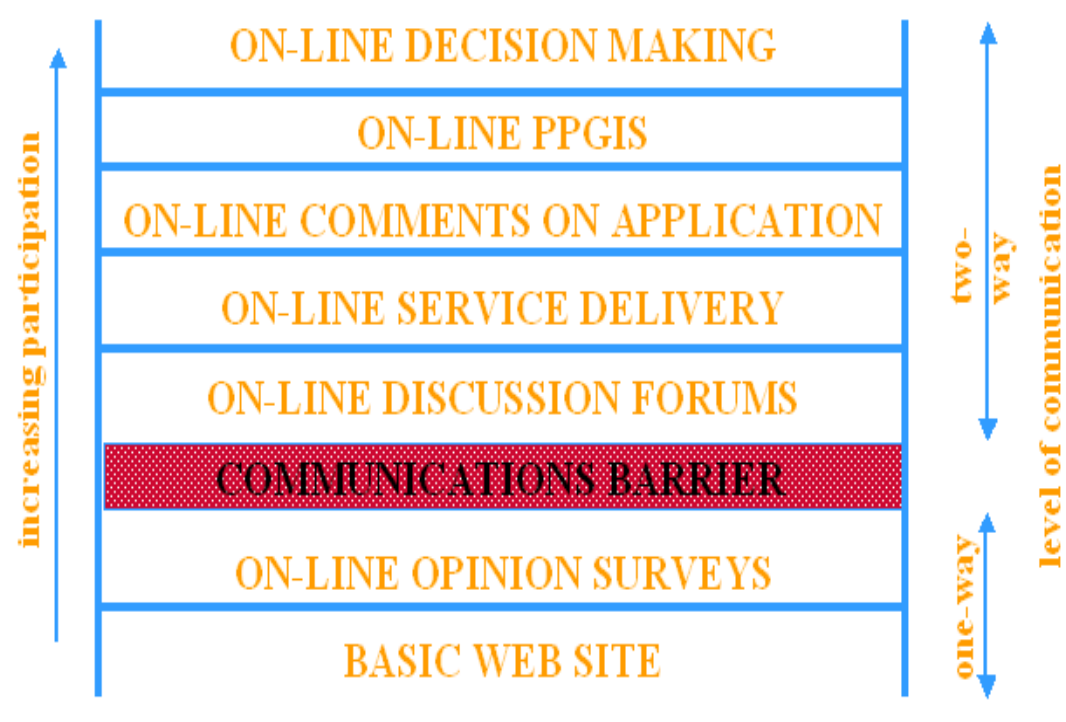

Source: Carver (2001)

In Figure 1, Carver suggests that the most inhibiting factor into moving e-participation forward is 'communication'. Therefore, a 'new model of e-participation' should place communication on the first rung instead of prioritising it later in the ladder of participation. Cooperating organisations will then be positioned to better define both short and long term strategies to achieve both individual and organisational goals.

While there has been an extension to the role of citizen planners, there must be delineation between the activist or citizen in relation to the professional planner who may also play an activist role. A professional planner brings a toolkit that uses recognised standards when applying policies and procedures. Applying these methods to neighbourhood plans requires customisation to reflect unique aspects of the community. However, it is expected that these plans are designed to be generalised with standards that create supported, accurate, reliable and unbiased results. The definition of participation has significantly changed in design and definition from Arnstein (1969) to Carver (2001). PPGIS offers a means for advanced technology-based citizen participation. All technologies are contradictory, however, and GIS is no exception, for PPGIS simultaneously empowers and marginalises people and communities (Harris and Weiner, 2002). 
Figure 2 suggests that the 'citizen' as a proxy for neighbourhood groups and non-profits, has the potential for an integrated, not just symbolic, role. In addition, Figure 2 suggests that GIS technology reduces the citizen reliance in data collection, evaluation, and reporting while increasing participation in program implementation, value/goals definition, monitoring and data maintenance. The level of engagement is subject to how well the technology barriers are overcome and the ability and/or willingness of the citizen to manage responsibilities when using advanced technologies. Outlined below are some ways to consider concepts and terms within advanced technology-based citizen participation using the Thompson technology tree model.

Figure 2 Thompson technology tree

\begin{tabular}{|c|c|c|}
\cline { 2 - 3 } \multicolumn{1}{c|}{} & Thompson Technology Tree & \multicolumn{1}{c}{} \\
\hline \multirow{2}{*}{ Citizen } & $\begin{array}{c}\text { Municipality or } \\
\text { university }\end{array}$ \\
\hline$\wedge$ & $\begin{array}{c}\text { Technology-based decision } \\
\text { support }\end{array}$ & $>$ \\
\hline$\wedge$ & maintenance & $>$ \\
\hline+ & Program implementation & + \\
\hline+ & Evaluation/reporting & + \\
\hline$>$ & Data collection & $\wedge$ \\
\hline$>$ & Training/education & $\wedge$ \\
\hline$>$ & Phased project plans & + \\
\hline+ & Partnership & + \\
\hline+ & Values/goals definition & + \\
\hline+ & Communication & $\wedge$ \\
\hline$>$ & Identification & + \\
\hline
\end{tabular}

Notes: Legend: $>=$ reliance; ${ }^{\wedge}=$ primary driver/coordinator; $+=$ equal participation

Source: Thompson $(2010)^{1}$

In this scenario, there are many 'branches' in the development of technology-based citizen planning. The process is not linear but iterative and, in practice, has many points of feedback that loop back, reflect and develop new strategies for moving ideas forward. The process of identifying how and when citizens can support the management of their public resources is not solely at the discretion of the municipality. As outlined below, the understanding of PPGIS roles and interpreting these has changed over time:

- 'Partnership' - The concept of what a partner is and what contributions are made by each participant changes over time. There are times when the initial stages of a technology project must be 'driven' by the university or municipal partner but in constant consultation with the $\mathrm{CBO}$. There is significant amount of time that must be taken to educate the $\mathrm{CBO}$ on the benefits or risks of a particular GIS strategy so that informed decisions can be made by all. 
- 'Data' - The power that data has in the ability for the partners to participate is more important than ever. Access to data is becoming less onerous due to the public 'right to know' and multiple formats that are compatible with GIS. The issue of who owns the data, how it can be used, distributed and maintained will be a negotiated issue throughout the project process.

- 'Independence/reliance' - It should be the goal for the citizen planner, and its related organisation, to become independent from the university-municipal partners in order to manage their own GIS. By having specific and measurable goals, the $\mathrm{CBO}$ will be able to track progress and determine where in the process of full implementation their customised GIS remain.

- 'Training/education' - In order for PPGIS to expand beyond a concept and towards a 'science' there must be a way to document the knowledge transfer and brand the policies, practice and methods into measureable, quantifiable and verifiable terms. The partner knowledge, that includes tangible and intangible concepts, can be shared in future partnerships or can be demonstrated through best practices by $\mathrm{CBO}$ sister agencies.

As Ghose (2001) suggested, “...there is a need to follow up such work with evaluations on how community organizations actively use GIS in their daily planning activities, on what types of policy changes they are able to bring with such information empowerment and on whether the introduction of GIS within community organizations creates its own set of power relations between those who possess the new technical skills and those who do not".

The stages of a typical PPGIS initiative include collecting data, working to record data digitally, analysing data, maintaining and updating data, and communicating a shared vision of the community's strengths and weaknesses (Weiner et al., 1995). In New Orleans, the vision was redefined by citizens through the city-wide recovery planning process and their goals at the neighbourhood level.

\section{$2.1 \quad P P G I S$ and BUCRP}

Post-Katrina 'citizen planners' began to emerge as the leaders in developing new mechanisms for conveying community concerns with the city administration. One such organisation was the Beacon of Hope Resource Centre (BOH) located in neighbourhood of Lakeview. The remainder of this paper describes how the $\mathrm{BOH}$ participated in a public participation geographic information systems (PPGIS) program to support its goal to influence policy by collecting and analysing neighbourhood condition data. The results of this community-university-municipal partnership can inform the planning process for communities who are emerging or are recovering from both natural and man-made disasters.

The BOH is a neighbourhood-based organisation developed after Hurricane Katrina. Since 2005, the BOH has collected parcel level data from the City of New Orleans Department of Code Enforcement for blight identification, tracked neighbourhood recovery, and use this as a basis for both residential and commercial reinvestment. The $\mathrm{BOH}$ model also included the adoption of the Beacon MODEL by existing 
neighbourhood groups who would be provided with resources including GIS services. The MODEL includes 'mapping, outreach, development, engagement and leadership' (Beacon of Hope/University of New Orleans Community Recovery Project, 2011).

During the summer of 2008, Milissa Orzolek, a University of Washington Geography graduate student, helped $\mathrm{BOH}$ bring survey production into a digital medium by introducing the organisation to the software capabilities of ArcGIS. The method of collecting data was rudimentary and while systematic in the method of collection through a block captain system, lacked the internal structure to efficiently manage data for multiple Beacon sites. Although the first phase maps and surveys were immensely popular. However, the growing time constraints of producing such maps and surveys, along with the more complex analyses residents now demanded, necessitated the hiring of more staff, which was limited due to the lack of funding (Baldwin and Thompson, 2010).

The Beacon of Hope/University of New Orleans Community Recovery Project (BUCRP) pilot began in September 2008. There was room for helping this organisation by providing graduate assistant staff time and management expertise from The University of New Orleans/Department of Planning and Urban Studies to help organise and strengthen the current Beacon GIS. This partnership started as a university/non-profit collaboration, one in which the non-profit stood to benefit from the time and resources of a large, state institution. A primary partnership goal would ensure that $\mathrm{BOH}$ would be independent of the University after receiving GIS training including survey standardisation, data maintenance, metadata development, reporting and processing documentation, to ensure that when future staff turnover occurred, anyone would be able to continue the work process. With a lack of staff and time to develop an in-house PPGIS, $\mathrm{BOH}$ relied on the University of New Orleans, specifically the Department of Planning and Urban Studies, for project management and GIS expertise.

The project provided then Master of Urban and Regional Planning graduate student Brian Baldwin with a service-learning opportunity. During the pilot project, university support immediately focused on evaluating existing methods of data collection and mapping services that were being provided to block captains. While this was an inaugural experience for the graduate assistant, Dr. Michelle Thompson had been involved with similar PPGIS projects.

In November 2004, Dr. Thompson led a team of Cornell University students in an advanced GIS service learning course which was a PPGIS project with the Dudley Street Neighbourhood Initiative (DSNI) in Roxbury, Massachusetts. The DSNI Administrator, Jason Webb, “...praised them for responding to our entire list of needs and listening to the community ideas rather than imposing top-down solutions" (Myers, 2011b).

In August of 2008, the BUCRP, a successful pilot community/university collaboration, was started to assist the Beacon of Hope Resource Centre (BOH) with mapping and surveying. Under the direction of Dr. Michelle Thompson and with the assistance of Brian Baldwin of the University of New Orleans - Department of Planning and Urban Studies, (now executive director) Tina Marquardt, $\mathrm{BOH}$ operations, the BUCRP continued and expanded the BOHs mapping program. 
After a program assessment, it was determined that the BUCRP should assist with development of a program to standardise existing survey instruments, retrain on data collection methods provide onsite training and implement Beacon of Hope Geographic Information System (BOH GIS) protocol and practice. Immediately, the value of using GIS for data analyses and graphic presentation, at first seen by focus groups, was presented to numerous residents and local government. Over time, these mapping results have been used to gauge recovery, identify infrastructure problems and blight, and encourage businesses and residents to return.

As stated in the initial project proposal, "The Beacon of Hope-University of New Orleans Community Recovery Project (BUCRP) was borne to organize, support, and document the creation of a Beacon GIS that allows flexibility in data collection, maintenance, mapping, and analysis across multiple platforms using a variety of public and private data sources".

The BUCRP was hampered due to lack of adequate public GIS data and plotting until a partnership was formed with Lynn DuPont, senior planner/GIS coordinator, from the Regional Planning Commission in the Fall of 2008. The BUCRP then reflected many of the traditional values that community/municipality/university partnership, as described, using PPGIS methodology.

By late Fall 2008, BUCRP produced a 1:2,100 condition map of the New Orleans Lakeview neighbourhood with 7,197 parcels. This map was brought to neighbourhood meetings and residents used the spatial representation of their survey data to consider new policy initiatives prioritised areas of critical need.

Starting in spring 2009, the stimulus that allowed the BUCRP to develop and expand the pilot into a program was both the Louisiana Disaster Recovery Foundation (LDRF) grant and the UNO pro bono services. The BOH began to expand their service areas from Lakeview into Gentilly neighbourhoods. This shift required significant time and effort to create the surveying and mapping tools, provide resident training, and produce condition maps with the data that was collected by each neighbourhood. Through a year of intense work, and lessons learned, the partnership between The University of New Orleans and The $\mathrm{BOH}$ and the Regional Planning Commission developed a viable public participation geographic information systems (PPGIS).

Setting itself apart from other condition surveys that have been conducted in post-Katrina New Orleans, the $\mathrm{BOH}$ maintained that neighbourhood surveys are conducted by the residents of the affected neighbourhood. Interested residents contact the $\mathrm{BOH}$ to establish a new Beacon and are provided with supplies, training and support to develop a survey (block) captain system. The 2006 neighbourhood condition surveys and maps were produced by hand and summarised using spreadsheets. Typically the results were discussed during community meetings which limited the status updates to those residents attending meetings, or who received the periodic neighbourhood needs, on the status of the neighbourhood's recovery. The early stages in the development of the Beacon GIS involved organising the existing data and most importantly, documenting the processes for creating and managing all of this data. All of the Beacon GIS data needed to be cleaned and organised to ensure that any new GIS manager could continue the $\mathrm{BOH}$ GIS with minimal problems. 
Figure 3 Lakeview property conditions (see online version for colours)

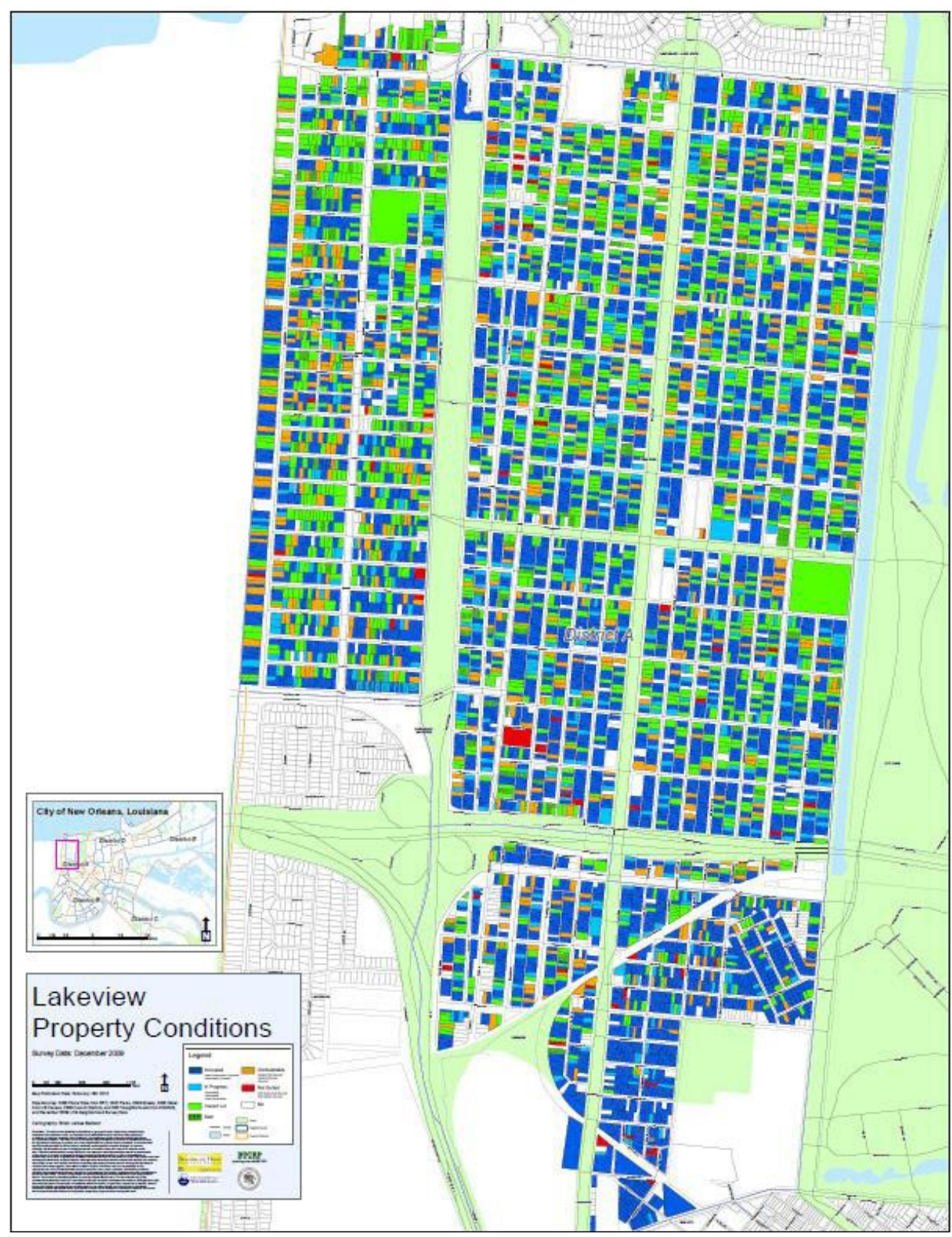

Source: Beacon of Hope/University of New Orleans Community Recovery Project (BUCRP) $(2009,2011)$ available at http://planning.uno.edu/BUCRP/ (accessed on 10 July 2011)

Residents in Beacon services areas, and beyond, increasingly began to identify and report potentially 'blighted' properties to city authorities and act in a coordinated effort. The ability to communicate their needs using both survey data and mapping increased the 
efficiency of reporting but also allowed municipal government to quickly identify the properties since the underlying parcel addresses were the same. The ability for the city to identify the properties that were/are of concern to the neighbours reconfirmed the fundamental need to share the same parcel layer file and to create a system whereby periodic updates were provided to the community. Other cities allow residents to consume city data through web portals and this is expected to be a part of the CNOGIS services in the future. With approximately 50,000-60,000 vacant and abandoned properties, the city recognised a critical threat to neighbourhood vitality, property values and tax base, public safety, recovery and economic growth (City of New Orleans, 2010a). While many organisations will have the ability to obtain the shapefile and use it as the base layer for their community data, it is imperative that the metadata be included that will provide adequate knowledge of its structure, exclusions and exemptions.

During a meeting with the Beacon of Hope Administrators and the Lakeview Civic Improvement Association (LCIA), it became apparent that the data definitions used by survey teams collecting community data were incongruent. When discussing how the LCIA data could be updated with and used by $\mathrm{BOH}$, the discussion of the survey standards was discussed. One member of the LCIA noted that when surveying the neighbourhood, if it was known that a property that was formerly part of the (NORA) Lot Next Door program was purchased by the adjacent homeowner, that she would mark the LND parcel as 'occupied'. The author explained that the definition of 'occupied' relates only to a structure (whether residential or commercial) and not based upon the purchase of the property (that has not been merged into a single parcel by the Registry of Deeds) only. A GIS can legitimate local information (which is important) and enable local people to use a modem argument, or it can legitimate bad data (which is disastrous) (Abbott, 1998).

While $\mathrm{BOH}$ was able to gain access to datasets through partnerships with other non-profits and organisations, the partnership with UNO opened up broader access to data and regional networks. Early in the BUCRP process, an agreement was made between the Regional Planning Commission (RPC) and BUCRP that printing of large scale maps would be provided gratis. Without this help, the BUCRP would have been unable to produce the many large scale maps that were used in meetings and distributed to community group. The RPC partnership was beneficial in terms of technical advice and professional relationships with local, regional and national private and municipal GIS professionals. The RPC provided 2009 aerial imagery for neighbourhoods that the BUCRP was working in. The RPC also provided a myriad of other important data files that aided the BUCRP in the production and analysis of their maps. The customised survey or 'walking' maps (Figure 4) increased the efficiency and accuracy of the survey process. Throughout the process, the maps were a means to communicate, educate and empower residents.

The standards, organisation and systems management provided by the university partnership advanced the development of the 'Beacon GIS'. BOH began to learn how to use technology to develop, maintain and deliver GI results in a manner than mirrors traditional data delivery organisations. However, this or any 'community information system' should be considered a replica of a GIS that applied theories, methods or standards set by the federal geographic data committee. 
Figure 4 Milneburg team walking map (see online version for colours)

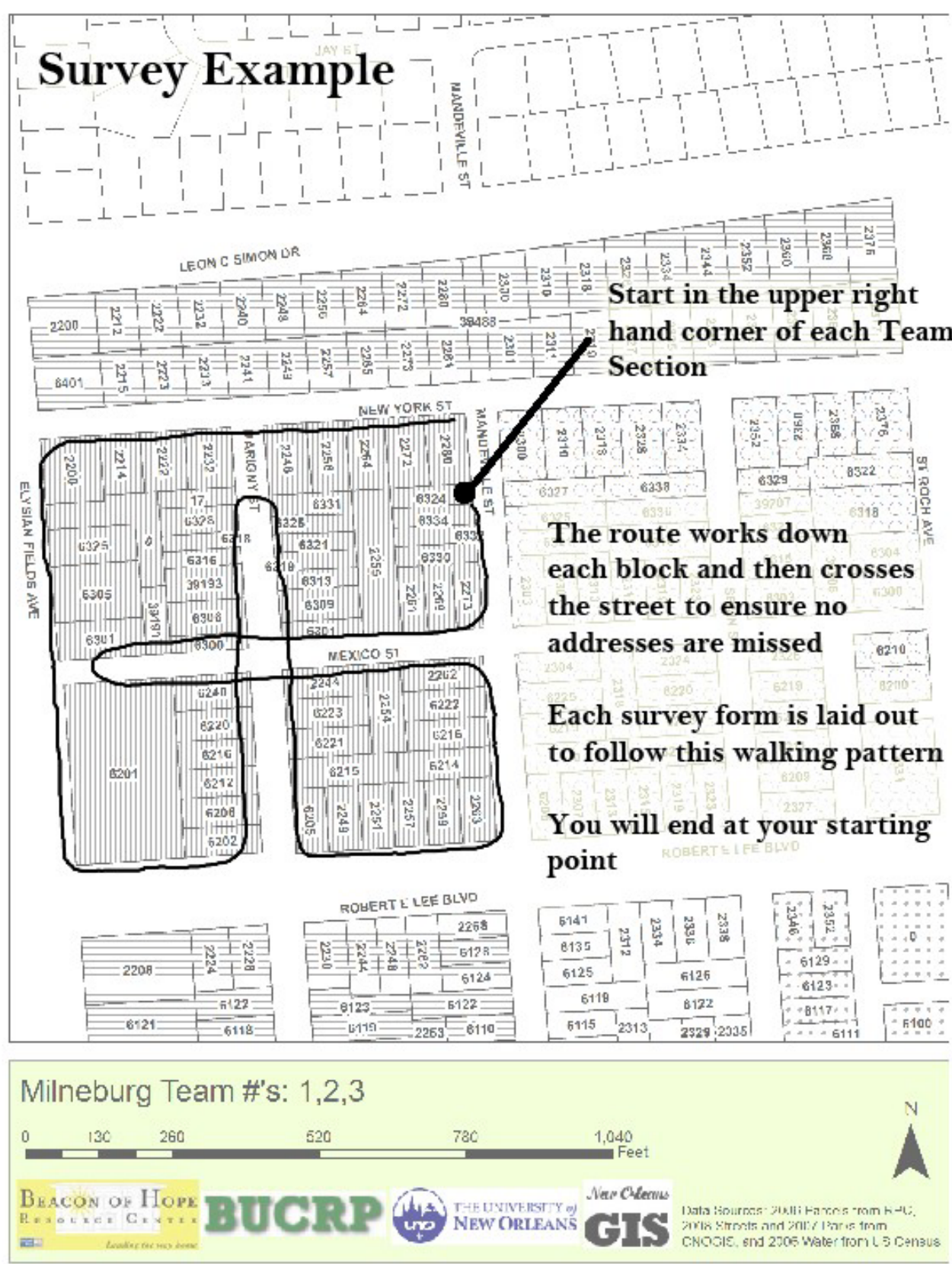

Source: Baldwin and Thompson (2010)

Ghose (2001) suggests that GIS needs to be transformed into community information systems (CIS) whereby a sophisticated users community gains access directly to spatial information technology and public data as well as the opportunity to build its own community dataset, and is aware of the kinds of questions to ask and the types of 
analyses to conduct so that its voice can be heard throughout the information-gathering and decision-making processes. The lack of spatial thinking was apparent at the beginning of the project with the $\mathrm{BOH}$. Prior to the partnership, the cartography and layout of maps was secondary to their production. The partnership showed $\mathrm{BOH}$ that the production of high quality maps, with recognised standards, would only aid in the map reliability and credibility of the organisation. Both the Regional Planning Commission (RPC) and University of New Orleans, Department of Planning and Urban Studies (UNO-PLUS) maintain that since the maps were distributed and viewed publicly, it was imperative that quality work be created in making these maps, data, and reports. Further, it was important to both RPC and UNO-PLUS that the data have the ability to seamlessly integrate with city, state and federal datasets. According to Lynn Dupont, senior planner/GIS manager with the RPC, "Data and information that you collect for one thing can always be used for two or three things in the future, and it's important we connect it with efforts going on with the city, especially in terms of housing conditions" (Myers, 2011a, 2011b).

The development of the BOH/UNO-PLUS/RCP community/university partnership started with an idea, developed into a pilot then a program that was outlined in a data sharing agreement. The creation of a data sharing agreement and contract for GIS services worked towards ensuring that the terms and goals of the relationship were understood by all parties. The BUCRP required that that all maps and data would be publically available. The BUCRP partnership's goal was to ensure that $\mathrm{BOH}$ would not be reliant on the university at the end of the project which is consistent with typical PPGIS program planning. To that end, BOH GIS would be sustainable and not be tied to university expertise or technology post project. There was also agreement that the 'practice of GIS' would try to follow the policy, procedures and practices of the Federal Geographic Data Committee (FGDC). While any of the practices were adopted, the data structures and variables identified by $\mathrm{BOH}$ did not immediately meet these requirements.

Until February 2011, the lack of access to the City of New Orleans parcel layer inhibited intra-agency or inter-community data sharing. While the City of New Orleans parcel layer is not $100 \%$ accurate, it remains the best base layer for creating the condition maps of each neighbourhood. Priority public data, such as blight, can be layered using the unique city parcel identification number or geopin.

In keeping with the goal of community engagement, participation has been improved through the BUCRP process through direct citizen input and cooperation at resident meetings. In the spring of 2009, BOH/UNO-PLUS applied for a grant through the Louisiana Recovery Disaster Foundation (LDRF) to provide support for the BUCRP project. To conduct a pilot surveying and mapping project of five neighbourhoods in Gentilly, BOH was awarded $\$ 25,000$ through the LDRF. This award provided the BUCRP with recognition and the ability to financially support its operation. The grant proved to $\mathrm{BOH}$ that the creation of a Beacon GIS could play an important role in the organisations funding opportunities.

After the first condition maps were created, some residents noted that houses and addresses were missing from the maps. To correct this issue and improve the overall accuracy of the surveys, residents edited their field maps and submitted these corrections to the BUCRP for inclusion in the next field survey. While these corrections may be more accurate than the City of New Orleans data, diverging from the standardised parcel will create future problems when the BUCRP wants to compare neighbourhood conditions 
with other datasets. Yet, this process and the incorporation of local knowledge have helped create more accurate representations of what exists on the ground.

Until February 2011, the lack of access to the City of New Orleans parcel layer inhibited intra-agency or inter-community data sharing. While the City of New Orleans parcel layer is not $100 \%$ accurate, it remains the best base layer for creating the condition maps of each neighbourhood. Priority public data, such as blight, can be layered using the unique city parcel identification number or geopin. It is hoped that the combination of community survey, to identify gaps in the city address list and the parcel layer, can be improved with a feedback system.

In May of 2010, the BUCRP phased out. From 2010-2011, the BOH has established additional 'Beacon' neighbourhood sites and has developed a close working relationship with the Lakeview Civic Improvement Association (LCIA). To support, and in recognition of the importance of the Beacon CIS, BOH hired an in-house staff person in the summer of 2010. UNO/PLUS provided BOH with a Beacon GIS 'best practices guide' in the hope that the BUCRP best practices will be maintained at the conclusion of the partnership.

\section{Summary/future directions}

As the menu of options available to use GIS emerges, so have the opportunities that public participation GIS (PPGIS) offers to community-municipal-university partnerships. The fundamental approach to PPGIS is based upon a model of community participation has also been transformed due to technology beyond GIS. PPGIS information is advantageous because it can be presented to policy-makers in a form, and at a scale, which they find credible and usable. The question then is whether such a 'participatory GIS' would simply be extractive, or whether it could empower local voices to more effectively influence policy (Harris and Weiner, 1998).

As a result of the successful PPGIS, the BUCRP has contributed to future projects that have increased capacity of $\mathrm{BOH}$ and expanded their ability to provide community services. For example, in the spring of 2011, BOH was awarded a contract for services from the state office of community development - disaster recovery unit to provide 'case management services' for 1,000 option 1 residents who did not and not in compliance (Myers, 2011a).

One should not question that the intent of community based organisations to fill gaps in service and representation are vital. It becomes a concern when these services are assumed to be transferable from CIS to GIS. Some of the real value of a participatory GIS, or perhaps more appropriately termed community-integrated GIS, will come if it can help to inform process and relationships, rather than simply extracting patterns from large volumes of data, which conventional GIS are best at (Harris and Weiner, 1998). Post-disaster these relationships can be forged more quickly if the goals of recovery are similar. Informed decisions can also be considered successful if technology is used as a means to equally share ideas and information between and within in the public, private and non-profit sectors.

The fundamental question: "how does GIS affect the ways in which communities are able to build awareness of their surroundings, develop consensus, and argue persuasively for a better future?" (Goodchild, 2002) In answer to this, the University of New Orleans Department of Planning and Urban Studies unveiled the 'WhoData.org' internet mapping 
service website to begin the transformation from providing geographic information data sets to services (Krupa, 2011). This decision support tool is the next logical phase in PPGIS development. The city parcel layer is the foundation for community data where public or private data can be integrated, displayed, mapped and analysed in an open and freely accessible website. By collecting neighbourhood data in a standardised way and with training for residents or volunteers, this user-generated content may more readily inform and inspire those who continue to invest in the new New Orleans.

\section{References}

Abbott, J., Chambers, R., Dunn, C., Harris, T., de Merode, E., Porter, G., Townsend and Weiner, D. (1998) 'Participatory GIS: opportunity or oxymoron', PLA Notes, Vol. 3, No. 3, pp.27-34.

ACORN/University Collaborative (2007) The People's Plan for Overcoming the Hurricane Katrina Blues: A Comprehensive Strategy for Building a More Vibrant, Sustainable, and Equitable 9th Ward, available at http://www.neworleans.ACORN.org (accessed 10 July 2011).

Baldwin, B. and Thompson, M. (2010) Beacon of Hope Resource Centre and the University of New Orleans Department of Planning and Urban Studies from 2008-2010, BUCRP Final Report, May 2010.

Beacon of Hope/University of New Orleans Community Recovery Project (BUCRP) $(2009,2011)$ available at http://planning.uno.edu/BUCRP/ (accessed on 10 July 2011).

City of New Orleans (2010a) Blight Strategy, available at http://www.nola.gov/PRESS/ City\%20Of\%20New\%20Orleans/All\%20Articles/MAYOR\%20UNVEILS\%20COMPREHEN SIVE\%20BLIGHT\%20ERADICATION\%20STRATEGY (accessed on 10 July 2011).

City of New Orleans (2010b) City Master Plan and Comprehensive Zoning Ordinance, Vol. 2, Community Participation Program, available at https:/www.communicationsmgr.com/ projects/1371/docs/Vol2_Ch15_Community_Participation_Program.pdf (accessed on 10 July 2011).

Carver, S., Evans, A., Kingston, R. and Turton, I. (2001) 'Public participation, GIS, and cyberdemocracy: evaluating on-line spatial decision support systems', Environment and Planning, Vol. 28, No. 6, pp.907-921.

Corburn, J. (2003) 'Bringing local knowledge into environmental decision making: improving urban planning for communities at risk', Journal of Planning Education and Research, Vol. 22, No. 4, pp.420-433.

Dudley Street Neighbourhood Initiative, available at http://www.dsni.org (accessed on 10 July 2011).

Federal Geographic Data Committee, available at http://www.fgdc.gov (accessed on 10 July 2011).

Gans, H. (1991) People, Plans, Policies: Essays on Poverty, Racism, and Other National Urban Problems, Columbia University Press, New York.

Ghose, R. (2001) 'Use of information technology for community empowerment: transforming geographic information systems into community information systems', Transactions in GIS, Vol. 5, No. 2, pp.141-163.

Goodchild, M. (2002) 'Foreword', W.J. Craig, T.M. Harris and D. Weiner (Eds): Community Participation and Geographic Information Systems, Taylor and Francis, London.

Handler, J. (1996) Down From Bureaucracy: The Ambiguity of Privatization and Empowerment, Princeton University Press, Princeton, New Jersey.

Harris, T. and Weiner, D. (1998) 'Empowerment, marginalization and community - integrated GIS', Cartography and Geographic Information Systems, Vol. 25, No.2, pp.67-76.

Harris, T. and Weiner, D. (2002) Community Participation and Geographic Information Systems, Taylor and Francis, London. 
Healy, P. (1997) Collaborative Planning: Shaping Place in Fragmented Societies, University of British Columbia, Vancouver.

Kheir, A-K. (1999) 'Visualization tools and public participation from crayons to computers', Critical Planning, available at http://www.spa.ucla.edu/critplan/past/volume006/index.htm (accessed on 10 July 2011).

Krupa, M. (2011) 'New Orleans blight websites get varied responses from City Hall', Times Picayune, available at http://www.nola.com/politics/index.ssf/2011/02/separate_blighttracking_websi.html (accessed on 10 July 2011).

Myers, B. (2011a) 'Data processors want standard in collecting road home info', City Business, available at http://neworleanscitybusiness.com/blog/2011/03/02/experts-want-standard-incollecting-road-home-data/ (accessed on 10 July 2011).

Myers, L. (2011b) 'Students help empower residents of once-ravaged Boston neighbourhood', Cornell Chronicle, available at http: //www.news.cornell.edu/chronicle/04/12.9.04/ Dudley_St_project.html (accessed on 10 July 2011).

Neighbourhood Planning Network (NPN) (2011) available at http://www.npnnola.com/ (accessed on 10 July 2011).

Nelson, M., Ehrenfeucht, R. and Laska, S. (2007) 'Planning, plans and people: professional expertise, local knowledge, and governmental action in post-Hurricane Katrina New Orleans', Cityscape: A Journal of Policy Development and Research, Vol. 9, No. 3, pp.23-52, available at http://ssrn.com/abstract=1090161.

New Orleans Redevelopment Authority Lot Next Door Program, available at http://www.npnnola.com/issues/view/16/the-lot-next-door-program (accessed on 10 July 2011).

Talen, E. (1999) 'Constructing neighbourhoods from the bottom up: the case for resident generated GIS', Environment and Planning, Vol. 26, pp.533-554.

Talen, E. (2000) 'Bottom-ip GIS: a new tool for individual and group expression in participatory planning', Journal of the American Planning Association, Vol. 66, No. 3, pp.279-294.

Thompson, M. (2010) 'Using PPGIS for neighbourhood reinvestment in weak market cities and post-disaster communities', International Journal of Data Mining, Modelling, and Management: Future GIS: Riding the Wave of a Growing Geospatial Society, forthcoming.

University of New Orleans, Department of Planning and Urban Studies (2010) The Beacon of Hope/University of New Orleans Community Recovery Project (BUCRP): Final Report. UNO/PLUS.

Weiner, D., Warner, T., Harris, T.M. and Levin, R.M. (1995) Apartheid Representations in a Digital Landscape: GIS, Remote Sensing, and Local Knowledge in Kiepersol, South Africa', Cartography and Geographic Information Systems, Vol. 22, No. 1, pp.30-44. 